\title{
$\nabla$ \\ Phototherapy promotes healing of cutaneous wounds in undernourished rats
}

Saulo Nani Leite ${ }^{1}$

Daniela dos Santos Masson-Meyers ${ }^{3}$

Chukuka S. Enwemeka ${ }^{3}$
Thiago Antônio Moretti de Andrade ${ }^{1,2}$

Marcel Nani Leite ${ }^{1,2}$

Marco Andrey Cipriani Frade $e^{1,2}$

Abstract: BACKGROUND: Various studies have shown that phototherapy promotes the healing of cutaneous wounds.

Овлестіvе: To investigate the effect of phototherapy on healing of cutaneous wounds in nourished and undernourished rats.

Methods: Forty rats, 20 nourished plus 20 others rendered marasmus with undernourishment, were assigned to four equal groups: nourished sham, nourished Light Emitting Diode treated, undernourished sham and undernourished Light Emitting Diode treated. In the two treated groups, two 8-mm punch wounds made on the dorsum of each rat were irradiated three times per week with $3 \mathrm{~J} / \mathrm{cm}^{2} \mathrm{sq} \mathrm{cm}$ of combined 660 and 890nm light; wounds in the other groups were not irradiated. Wounds were evaluated with digital photography and image analysis, either on day 7 or day 14, with biopsies obtained on day 14 for histological studies.

RESULTS: Undernourishment retarded the mean healing rate of the undernourished sham wounds ( $p<$ 0.01), but not the undernourished Light emission diode treated wounds, which healed significantly faster $(\mathrm{p}<0.001)$ and as fast as the two nourished groups. Histological analysis showed a smaller percentage of collagen in the undernourished sham group compared with the three other groups, thus confirming our photographic image analysis data.

CONCLUSION: Phototherapy reverses the adverse healing effects of undernourishment. Similar beneficial effects may be achieved in patients with poor nutritional status.

Keywords: Nutritional marasmus; Phototherapy; Protein malnutrition; Wound healing

\section{INTRODUCTION}

Wound healing is an intense dynamic process that increases the metabolic demand for nutrients as restoration of the structural and functional integrity of damaged tissues progresses..$^{1-4}$ Local factors, such as infections, mechanical force, presence of 'foreign bodies' (e.g., steel or glass fragments) and the characteristics of the wound (size, location and type) can interfere with tissue repair. Although measures can be taken to overcome such challenges, systemic factors such as diabetes mellitus, circulatory deficiencies, hormonal imbalance and nutritional deficits, including protein-energy malnutrition (PEM), present greater problems. $^{1-5}$
PEM results from inadequate food intake and is characterized by energy deficiency, resulting from decreased intake of macro- and micronutrients. Three types of PEM are well-recognized; marasmus, kwashiorkor and marasmus-kwashiorkor. Marasmus is prevalent in most developing countries, and it is said to occur when energy intake is insufficient to meet the organic demand of the body, causing the body to use its own energy sources such as glycogen, skeletal muscle and finally triglycerides, to fulfill its energy requirements. $^{6-8}$ This results in significant weight loss - typically loss of muscle and adipose masses, growth retardation, muscle atrophy and "alert" mental status. Serum albumin levels are known to diminish but may not change significantly.,

\footnotetext{
Received on 02.01.2014

Approved by the Advisory Board and accepted for publication on 16.01.2014.

* Work performed at the Biotério do Departameto de Clínica Médica da Faculdade de Medicina de Ribeirão Preto - Universidade de São Paulo (FMRP-USP) - São Paulo, Brazil.

Financial support: FAEPA-HC-FMRP/USP e CNPq.

Conflict of interests: None.

Universidade de São Paulo (USP) - Ribeirão Preto (SP), Brazil

Narcisus Biotecnologia LTDA - Ribeirão Preto (SP), Brazil

University of Wisconsin-Milwaukee - Milwaukee, USA.

(C2014 by Anais Brasileiros de Dermatologia
} 
Kwashiorkor is attributable more to protein insufficiency than energy deficiency, and is associated with inadequate protein synthesis and edema. Kwashiorkor can also occur due to increased nutrient demand in patients with catabolic episodes, such as sepsis and burns. Anemia, hepatomegaly, lethargy, low levels of visceral proteins, severe immunological disorders and early death have been reported in individuals with kwashiorkor. ${ }^{6-8}$ Symptoms of marasmus and kwashiorkor appear in persons with marasmuskwashiorkor, and each condition-marasmus, kwashiorkor or marasmus-kwashiorkor- can significantly impair wound healing.

In recent years, phototherapy with red or infrared (600 - 1000nm) non-coherent light emitting diodes (LEDs) has been described as a valuable tool for promoting tissue repair. ${ }^{9-11}$ There is evidence that coherent light (laser) and non-coherent (LED) light produce similar healing effects on tissues, reinforcing the notion that the physiological and therapeutic effects of phototherapy depend on the absorption of photons by chromophores in the target tissue. Studies have shown that the absorbed energy (photon) is transformed into ATP and used by the cell to power needed metabolic activities, such as cell proliferation, collagen synthesis, and overall acceleration of tissue repair in experimental animal studies and humans with chronic wounds. ${ }^{11-23}$ Due to these emerging reports, we hypothesized that wounds, which in the presence of undernourishment are well-known to heal slowly or not at all, may benefit from treatment with the right dose and wavelength of light. To test this hypothesis, we determined the effect of a combination of $660 \mathrm{~nm}$ and $890 \mathrm{~nm}$ LED phototherapy on wound healing in undernourished rats with clinical evidence of marasmus. Our choice of combined $660 \mathrm{~nm}$ and $890 \mathrm{~nm}$ phototherapy was influenced by a previous study in which we showed that these light wavelengths significantly improved healing in patients with chronic venous ulcers. ${ }^{23}$

\section{MATERIAL AND METHODS}

\section{Experimental Induction of Marasmus}

Following approval by the Ethics Committee in Animal Research (CETEA), Ribeirão Preto School of Medicine, University of São Paulo (FMRP-USP) (Protocol Number 274/2005), 40 adult male Wistar rats (Rattus norvegicus) weighing $180-200 \mathrm{~g}$ were obtained from the central animal facility of FMRPUSP. To estimate the mean food intake of each rat, the animals were fed ad libitum during the first three days. Thereafter, 20 rats were randomly assigned to the ad libitum (nourished group); the remaining 20, assigned to the undernourished group, received half of the average daily food intake determined during the ini- tial three days. Animals received water ad libitum and were kept in individual cages in a room maintained at a temperature of $22^{\circ} \mathrm{C}$ with $12 \mathrm{~h}$ light/12h darkness cycles. After three days, rats were weighed and serum albumin measured in order to assess the nutritional status of each animal. The analysis was again carried out on the $60^{\text {th }}$ day of follow-up.

\section{Surgical Procedures and Assignment of Animals to Experimental Groups}

After 60 days of monitoring the nutritional status of the rats, they were anesthetized with intraperitoneal injections of $1.0 \mathrm{ml} / 100 \mathrm{~g}$ body weight of $4.0 \%$ chloral hydrate. Subsequently, two $8-\mathrm{mm}$ punch wounds were made on the dorsum of each rat before the animals were assigned to four equal groups; nourished sham (NS), nourished LED treated (NL), undernourished sham (US) and undernourished LED treated (UL). In the sham groups, the animals underwent the surgical procedure and were treated with LED off. Each procedure was performed in accordance with the ethical principles adopted by the Brazilian College of Animal Experimentation (COBEA).

\section{LED Phototherapy}

A Dynatron Solaris $705^{\circledR}$ device fitted with combined 660nm and 890nm Cluster Probe (Dynatronics Corporation, Salt Lake City, Utah, USA) was used to treat the NL and UL wounds, as detailed in our previous study [23]. The device emits 500-mW light from 36 diodes interspersed in a $5-\mathrm{cm}^{2}$ cluster-32 infrared 890-nm diodes, each emitting 15-mW; and four 5-mW red 660-nm diodes. To avoid cross contamination, each wound was covered with a transparent $100 \%$ transmissive clear plastic before the probe was placed directly on the wound, as detailed in our previous report. ${ }^{23}$ Wounds were then treated for 30 s each, yielding a dose of $3 \mathrm{~J} \mathrm{~cm}^{-2}$ fluence. Treatment was applied three times per week over a maximum period of 14 days.

\section{Wound Healing Assessment}

Photographs of each wound were taken with a Sony-DSC P41 digital camera (Sony Corporation, Tokyo - Japan) on days zero, 7 and 14. Image capture was standardized using a 30-cm-high aluminum support, to which the camera was fixed perpendicularly to the wound. The digital images obtained were analyzed with Image ${ }^{\circledR}$ software (U.S. National Institutes of Health, Bethesda, MD), as previously described. Subsequently, wound areas, which were clearly delineated by the software, were automatically computed. ${ }^{23-26}$ Thereafter, ulcer healing rates (UHR) (that is to say: initial area [Ai] minus the final area [Af] divided by the initial area [(Ai-Af)/Ai]), were calculated. ${ }^{23,26}$ 


\section{Histological analysis}

On the $14^{\text {th }}$ day post-surgery, animals were euthanized in a $\mathrm{CO}_{2}$ chamber; then wound areas were biopsied with 8-mm punches and immediately fixed in $4 \%$ formalin. Slides were stained with Gomory's trichrome for collagen analysis. Ten images from each slide-each with 500x100 pixels-were selected and then observed under a Leica DM 4000B microscope (Leica Microsystems, Cambridge, Essex, UK) at a magnification of 100x. A plug-in color analyzer from Image ${ }^{\circledR}$ software was used to delineate and quantify the blue areas representing collagen. The percentage of collagen in each area was thus computed.

\section{Statistical Analysis}

Rat body weights and serum albumin levels were compared using the t-Student test and Mann Whitney test for comparison between two samples. Group differences in UHR and collagen were determined with ANOVA; then, Bonferroni post-hoc tests were used to pinpoint groups that differed. The data were analysed using the GraphPad Prism 5 software (San Diego, CA, USA). The level of statistical difference was set at $\mathrm{p}<0.05$.

\section{RESULTS}

\section{Marasmus}

As shown in graph 1A, undernourished rats weighed significantly less than nourished rats at 60 days following diet modification $(p<0.001)$. Similarly, serum albumin levels were lower in the undernourished group; however, the difference was not statistically significant ( $p>0.05$ ); graph 1B. Undernourished rats had all the clinical signs of marasmus; notably, decreased growth, muscle atrophy, fragile nails, hair loss, permanent "alert" state, intense agitation and starvation.

\section{Ulcer Healing Rate}

Day seven data showed that undernourished sham (US) wounds healed significantly slower than any of the other wounds, and was statistically different from the NS group $(p<0.01)$, NL group $(p<0.05)$ and the UL group $(\mathrm{p}<0.001)$, as displayed in graph $2 \mathrm{~A}$. Treatment with LED phototherapy reversed this trend, such that UL wounds healed significantly faster than the US wounds $(p<0.001)$ and attained the same healing rate as treated or untreated nourished wounds (Graph 2A). Thus, phototherapy fully reversed the adverse healing effect of marasmus, restoring normal healing in the UL group. There was no statistically significant difference in the healing rates of nourished and undernourished wounds treated with phototherapy; neither were there differences in UHR between the UL and NL groups.

Postoperative day 14 data revealed a similar
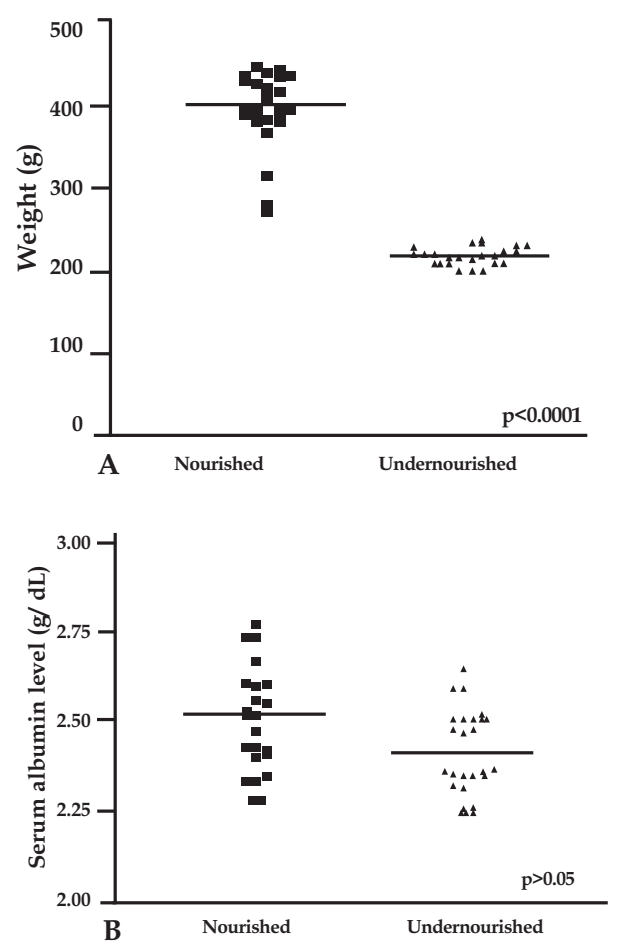

GRAPH 1: The relative weights (A) and serum albumin levels (B) of nourished and undernourished rats after 60 days of diet modification and observation before wounds were induced in the rats
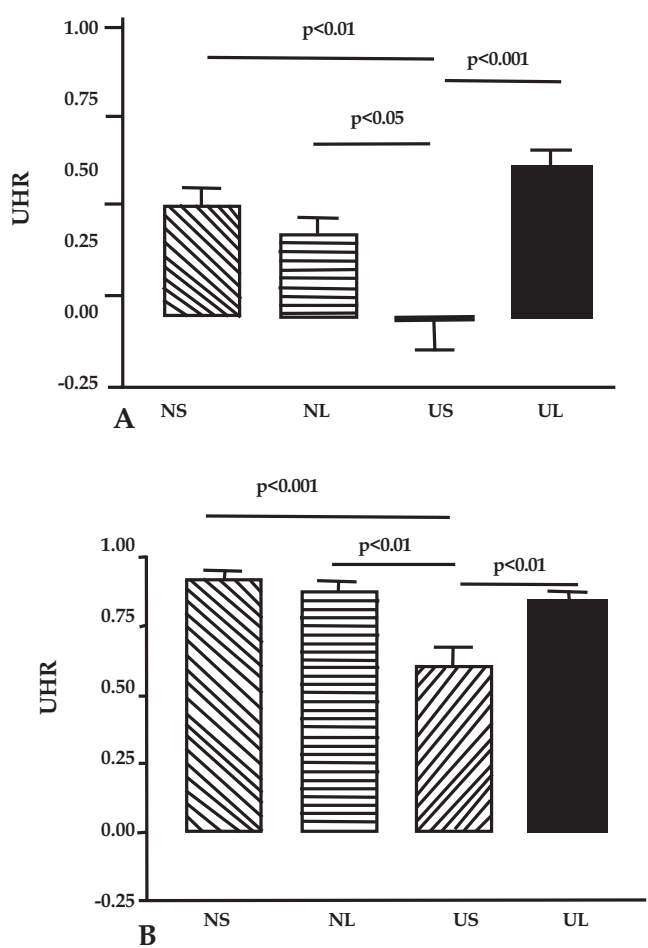

GRAPH 2: Mean ulcers healing rate (UHR) evaluated on the $7^{\text {th }}$ postoperative day (A) and the $14^{\text {th }}$ postoperative day (B) 
trend. As shown in graph $2 \mathrm{~b}$ and figure 1 , US wounds continued to heal slower than those of any other group, and were statistically significantly different from the UL and NL groups ( $<<0.01)$, as well as the NS group ( $p<0.001$ ). There were no statistically significant differences in UHR between the UL group and the two nourished groups, NS and NL ( $p>0.05$ ); again indicating that phototherapy reversed the adverse healing effects of marasmus (Graph 2B and Figure 1). As with the 7-day data, there was no difference between the healing rates of the NS and NL wounds (Graph 2B).

\section{Histological Evaluation of Healing}

As shown in graph 3 and figure 2, the US wounds also had a smaller percentage of collagen than those of any other group ( $p<0.01)$. Qualitative histological analysis showed that the healed tissue had a lighter blue color-different from the normal collagen color seen in the other groups. The US group also had smaller, less dense collagen formation compared with the other groups (Figure 2). In contrast, the collagen of undernourished wounds, treated with LED phototherapy, was visibly superior compared with the US group and similar in appearance to the specimens from the two nourished groups (Figure 2).

\section{DISCUSSION}

Adequate levels of nutrients such as proteins, carbohydrates, vitamins and minerals are essential to maintain the normal structure and function of the

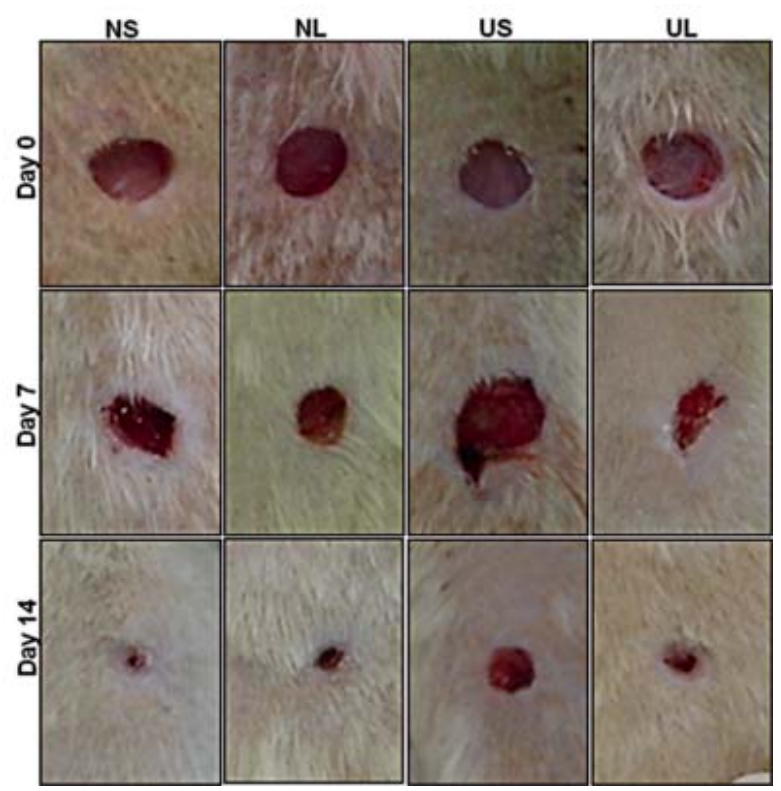

FIGURE 1: Representative photographs showing the four groups (NS, NL, US and UL) of wounds on day 0 , and the $7^{\text {th }}$ and $14^{\text {th }}$ postoperative days skin. When malnutrition occurs, healing can be impaired since the normal process of cutaneous tissue repair depends heavily on excellent nutritional status of patients. ${ }^{2,3,5,26,27}$ We induced marasmus in rats, created wounds and treated them with LED phototherapy in order to mimic the type of non-responsive wounds presented clinically by undernourished patients. Consistent with previous reports, our success in inducing marasmus in the animals was confirmed by significant weight loss, decreased growth, muscular atrophy, fragile nails, hair loss, permanent "alert" state, intense agitation and starvation., ${ }^{3,-8}$ Mean serum albumin declined in the undernourished group but was not statistically different from the mean level measured in the nourished group. This finding is consistent with previous reports, which indicate that serum albumin has a tendency to decrease slowly in

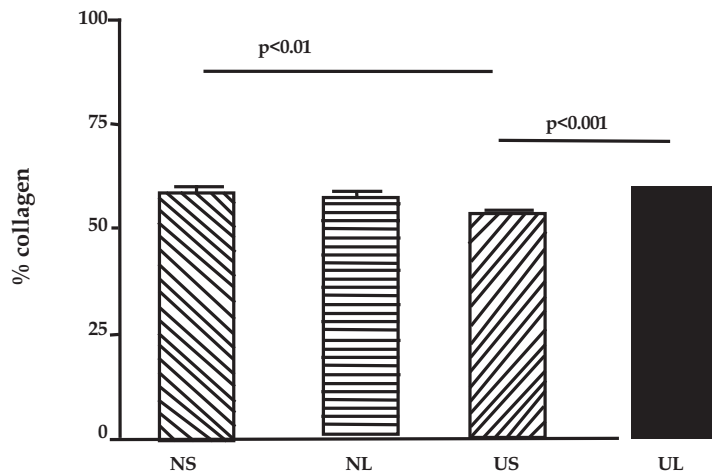

GRAPH 3: Percentage of collagen area quantified in each group of wounds on the $14^{\text {th }}$ postoperative day

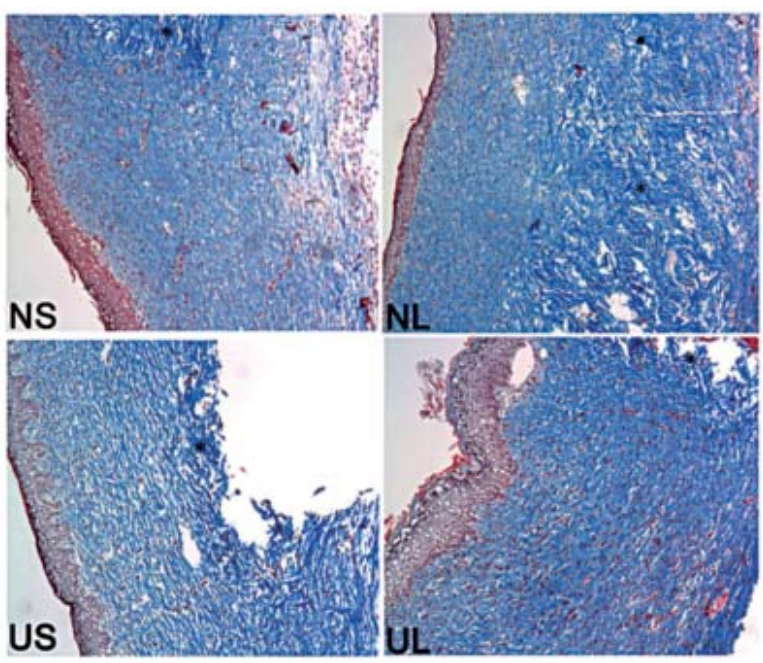

FIGURE 2: Representative light micrographs showing the collagen in the wounds of the groups NS, NL, US and UL on day 14 (Gomory trichrome stain). The asterisk $\left({ }^{*}\right)$ indicates normal collagen 
cases of marasmus., ${ }^{3,6}$ The UHR results obtained on days 7 and 14 showed that undernourishment significantly impaired cutaneous wound healing. These findings were corroborated by our histological findings, which showed that the sham undernourished (US) rats had the smallest percentage of collagen (Graph 3). Previous studies have shown that malnutrition impairs wound healing and delays the process of collagen synthesis. ${ }^{2,3,5,26,27}$

Phototherapy did not promote healing or alter the collagen of nourished rats. In contrast, it significantly accelerated wound healing in undernourished rats; reversing the adverse effect of marasmus such that the UL rats healed at the same rate as the two well-nourished groups. This finding suggests that healing advanced optimally with full nourishment but not in the presence of marasmus. It is possible that marasmus engenders the type of physiological condition that heightened the sensitivity of cells to light absorption and utilization. In an in vitro study, Almeida-Lopes et al. ${ }^{28}$ exposed two sets of gingival fibroblasts to $670 \mathrm{~nm}, 780 \mathrm{~nm}, 692 \mathrm{~nm}$ and $786 \mathrm{~nm}$ wavelengths of light. One set of cells were grown in an ideal culture medium with $10 \%$ fetal bovine serum (FBS); the other in a nutrient deficient medium (5\% FBS). Without phototherapy, the latter cells proliferated at a significantly lower rate than the cells grown in the ideal culture condition. Conversely, with phototherapy, they proliferated at similar or higher rates than those grown with the ideal medium..$^{28}$

Similarly, Pinheiro et al. irradiated cutaneous wounds in nourished and undernourished rats with light from a $635 \mathrm{~nm}$ laser or a polarized polychromatic 400 - 200nm light source, using either $20 \mathrm{~J} / \mathrm{cm}^{2}$ or $40 \mathrm{~J} / \mathrm{cm}^{2}$ fluence. ${ }^{29}$ With polychromatic light treatment, the best healing was observed in nourished and undernourished rats treated with a $20 \mathrm{~J} / \mathrm{cm}^{2}$ dose. With laser treatment, the best healing obtained was in the undernourished group treated with the $20 \mathrm{~J} / \mathrm{cm}^{2}$ fluence. ${ }^{29}$ These results, in addition to those of Almeida-Lopes, are consistent with our findings, which show that healing retardation-occasioned by undernourishment-can be reversed with treatment, using $3.0 \mathrm{~J} / \mathrm{cm}^{2}$ fluence of combined $660 \mathrm{~nm}$ and
$890 \mathrm{~nm}$ light. ${ }^{28}$ This finding suggests that a similar beneficial effect may be achieved in undernourished patients (e.g., those with vitamin or micronutrient deficiencies, chronic degenerative diseases such as AIDS, cancer, or metabolic pathologies), whose wounds are known to respond poorly to other forms of treatment. ${ }^{25,27,30}$

Although the mechanisms by which phototherapy promotes tissue repair is not fully understood, several studies have suggested that treatment with light, particularly red and infrared light in the range of 600 to $1000 \mathrm{~nm}$, accelerates local blood flow, speeds inflammation, promotes cell proliferation (including the proliferation of epithelial and endothelial cells, keratinocytes, macrophages, lymphocytes, and fibroblasts), increases collagen synthesis and overall, accelerates tissue repair in a variety of experimental models. ${ }^{16-20,31-37}$ Reports indicate that these beneficial effects are achieved because such wavelengths of light are readily absorbed by cytrochrome c oxidase - a chromophore within the inner membrane of mitochondria. ${ }^{12,13,15}$ In turn, the light energy absorbed is transformed into adenosine triphosphate (ATP): the form of energy that cells use to power needed metabolic processes, such as cell proliferation and tissue repair. ${ }^{11,14-16,19,20}$ Susceptibility to photostimulation seems dependent on the physiological status of the irradiated cells, given that in certain conditions, some cells have been shown to exhibit decreased redox potential and increased sensitivity to irradiation with light. ${ }^{11,13,38-41}$ Further studies are needed to elucidate the mechanisms by which light promotes tissue repair in the presence of marasmus.

\section{CONCLUSION}

Our results show that phototherapy, using a combination of $660 \mathrm{~nm}$ and $890 \mathrm{~nm}$ LEDs, significantly promotes healing of skin wounds in undernourished rats, suggesting that similar beneficial effects may be achieved in patients with poor nutritional status, such as those with chronic degenerative diseases such as AIDS, cancer or critically ill patients admitted to intensive care.] 


\section{REFERENCES}

1. Gurtner GC, Werner S, Barrandon Y, Longaker, MT. Wound repair and regeneration. Nature. 2008;453:314-21.

2. Broughton G, Janis JE. Wound healing: An overview. Plast Reconstr Surg. 2006;117:1e-S-32e-S.

3. Lee YS, Wysocki A, Warburton D, Tuan TL. Wound Healing in Development. Birth Defects Res C Embryo Today. 2012;96:213-22.

4. Sinno H, Prakash S. Complements and the Wound Healing Cascade: An Updated Review. Plast Surg Int. 2013;2013:146764.

5. Stechmiller JK, Cowan L, Logan K. Nutrition support for wound healing. Supp Line. 2009;31:2-8.

6. Kwiatkowsky CA, Touger-Decker R, O'Sullivan-Maillet. Aspectos nutricionais da saúde e da doença. In: Scanlan CL, Wilkins JK, Stoller JK, editores. Fundamentos da Terapia Respiratória de Egan. São Paulo: Brazil; 2000. p. 1104-1106.

7. International Food Biotechnology Committee. Appendix 4: Protein-energy malnutrition. Compr Rev Food Sci Food Saf. 2008;7:111-2.

8. Müller 0 , Krawinkel M. Malnutrition and health in developing countries. CMAJ. 2005;173:279-86.

9. de Sousa AP, de Aguiar Valença Neto Ade A, Marchionni AM, de Araújo Ramos M, dos Reis Júnior JA, Pereira MC,et al. Effect of LED Phototherapy (170020 nm) on TGF-b Expression During Wound Healing: An Immunohistochemical Study in a Rodent Model. Photomed Laser Surg. 2011;29:605-11.

10. Jahangiri Noudeh Y, Shabani M, Vatankhah N, Hashemian SJ, Akbari K. A combination of 670 and $810 \mathrm{~nm}$ diode lasers for wound healing acceleration in diabetic rats. Photomed Laser Surg. 2010;28:621-7.

11. Prindeze NJ, Moffatt LT, Shupp JW. Mechanisms of action for light therapy: a review of molecular interactions. Exp Biol Med (Maywood). 2012;237:1241-8.

12. Karu TI. Multiple Roles of Cytochrome c Oxidase in Mammalian Cells Under Action of Red and IR-A Radiation. IUBMB Life. 2010;62:607-10.

13. Karu TI. Low-power laser therapy. Biomed Photon Hand. 2003; 48-1-48-25.

14. Silveira PC, Silva LA, Fraga DB, Freitas TP, Streck EL, Pinho R. Evaluation of mitochondrial respiratory chain activity in muscle healing by low-level laser therapy. J Photochem Photobiol B. 2009;95:89-92.

15. Karu TI. Mitochondrial Mechanisms of Photobiomodulation in Context of New Data About Multiple Roles of ATP. Photomed Laser Surg. 2010;28:159-60.

16. Karu T, Pyatibrat L. Gene Expression Under Laser and Light-emitting Diodes Radiation for Modulation of Cell Adhesion. IUBMB Life. 2011 S:63:747-53

17. Kreisler M, Christoffers AB, Willershausen B, d'Hoedt B. Effect of low-level GaAlAs laser irradiation on the proliferation rate of human periodontal ligament fibroblasts: an in vitro study. J Clin Periodontol. 2003;30:353-8.

18. Hawkins $\mathrm{DH}$, Abrahamse $\mathrm{H}$. Time-dependent responses on wounded skin fibroblasts following phototherapy. J Photochem Photobiol B. 2007;88:147-55.

19. Silveira PC, Silva LA, Freitas TP, Latini A, Pinho RA. Effects of low-power laser irradiation (LPLI) at different wavelengths and doses on oxidative stress and fibrogenesis parameters in an animal model of wound healing. Lasers Med Sci. 2011;26:125-31.

20. Aparecida Da Silva A, Leal-Junior EC, Alves AC, Rambo CS, Dos Santos SA, Vieira RP, et al. Wound-healing effects of low-level laser therapy in diabetic rats involve the modulation of MMP-2 and MMP-9 and the redistribution of collagen types I and III. J Cosmet Laser Ther. 2013;15:210-6.

21. Sobanko JF, Alster TS. Efficacy of low-level laser therapy for chronic cutaneous ulceration in humans: A review and discussion. Dermatol Surg. 2008;34:991-1000.

22. Erdle BJ, Brouxhon S, Kaplan M, Vanbuskirk J, Pentland AP. Effects of continuous -wave (670-nm) red light on wound healing. Dermatol Surg. 2008;34:320-5.

23. Caetano KS, Frade MA, Minatel DG, Santana LA, Enwemeka CS. Phototerapy improves healing of chronic venous ulcers. Photomed Laser Surg. 2009;27:111-8.

24. Hewitt KM, Stringer MD. Correlation between the surface area of synovial membrane and the surface area of articular cartilage in synovial joints of the mouse and human. Surg Radiol Anat. 2008;30:645-51.

25. Minatel DG, Frade MA, França SC, Enwemeka CS. Phototherapy promotes healing of chronic diabetic leg ulcers that failed to respond to other therapies. Lasers Surg Med. 2009:41:433-41.

26. Demling RH. Nutrition, anabolism, and the wound healing process: an overview. Eplasty. 2009:9:e9.

27. Stechmiller JK. Understanding the Role of Nutrition and Wound Healing. Nutr Clin Pract. 2010;25:61-8

28. Almeida-Lopes L, Rigau J, Zângaro RA, Guidugli-Neto J, Jaeger MM. Comparison of the low level laser therapy effects on cultured human gingival fibroblasts proliferation using different irradiance and same fluence. Lasers Surg Med. 2001;29:179-84.
29. Pinheiro AL, Meireles GC, Carvalho CM, de Barros Vieira AL, dos Santos JN, Ramalho LM. Biomodulative Effects of Polarized Light on the Healing of Cutaneous Wounds on Nourished and Undernourished Wistar Rats. Photomed Laser Surg. 2006;24:616-24.

30. Little MO. Nutrition and skin ulcers. Curr Opin Clin Nutr Metab Care. 2013;16:39-49.

31. Samoilova KA, Zhevago NA, Petrishchev NN, Zimin AA. Role of nitric oxide in the visible light-induced rapid increase of human skin microcirculation at the local and systemic levels II: Healthy volunteers. Photomed Laser Surg. 2008;26:443-9.

32. Wu CS, Hu SC, Lan CC, Chen GS, Chuo WH, Yu HS. Low-energy helium-neon laser therapy induces repigmentation and improves the abnormalities of cutaneous microcirculation in segmental-type vitiligo lesions. Kaohsiung J Med Sci. 2008;24:180-9.

33. Fiório FB, Albertini R, Leal-Junior EC, de Carvalho Pde T. Effect of low-level laser therapy on types I and III collagen and inflammatory cells in rats with induced third-degree burns. Lasers Med Sci. 2014;29:313-9.

34. Peplow PV, Chung TY, Baxter GD. Laser photobiomodulation of wound healing: review of experimental studies in mouse and rat animal models. Photomed Laser Surg. 2010;28:291-325.

35. Reddy GK, Stehno-Bittel L, Enwemeka CS. Laser photostimulation of collagen production in healing rabbit Achilles tendons. Lasers Surg Med. 1998;22:281-7.

36. Gum SL, Reddy GK, Stehno-Bittel L, Enwemeka CS. Combined ultrasound, electrical stimulation, and laser promote collagen synthesis with moderate changes in tendon biomechanics. Am J Phys Med Rehabil. 1997;76:288-96.

37. Reddy GK, Stehno-Bittel L, Enwemeka CS. Laser photostimulation accelerates wound healing in diabetic rats. Wound Repair Regen. 2001;9:248-55.

38. Tafur J, Mills PJ. Low-Intensity Light Therapy: exploring the role of redox mechanisms. Photomed Laser Surg. 2008;26:323-8.

39. Lim J, Ali ZM, Sanders RA, Snyder AC, Eells JT, Henshel DS, et al. Effects of Low-Level Light Therapy on Hepatic Antioxidant Defense in Acute and Chronic Diabetic Rats. J Biochem Mol Toxicol. 2009; 23:1-8.

40. Firat ET, Dağ A, Günay A, Kaya B, Karadede Mi, Kanay BE, et al. The effects of low-level laser therapy on palatal mucoperiosteal wound healing and oxidative stress status in experimental diabetic rats. Photomed Laser Surg. 2013;31:315-21.

41. Karu TI, Pyatibrat LV, Kolyakov SF, Afanasyeva NI. Absortions measurements of cell monolayers relevant to mechanisms of laser phototherapy: Reduction or oxidation of cytochrome c oxidase under laser radiation at $632.8 \mathrm{~nm}$. Photomed Laser Surg. 2008;26:593-9.

How to cite this article: Leite SN, Andrade TAM, Masson-Meyers DS, Leite MN, Enwemeka CS, Frade MAC. Phototherapy promotes healing of cutaneous wounds in undernourished rats. An Bras Dermatol. 2014;89(6):899-904.

\author{
MAILING ADDRESS: \\ Marco Andrey Cipriani Frade \\ Av. Bandeirantes, 3900 \\ Bairro Monte Alegre \\ 14049-900 - Ribeirão Preto - SP \\ Brazil \\ E-mail: mandrey@fmrp.usp.br
}

